А.М. Кривоножко ${ }^{1}$, В.О. Явтушенко ${ }^{2}$ А.В. Самокіш ${ }^{2}$, С.С. Воробйов

${ }^{1}$ Командування ПвК “Центр”, Васильків

${ }^{2}$ Харківський національний університет Повітряних Сил ім. І. Кожедуба, Харків

\title{
РОЗРОБКА МЕТОДУ КОМПЛЕКСНОЇ НАВІГАЦІЇ БЕЗПІЛОТНОГО ЛІТАЛЬНОГО АПАРАТУ НА ОСНОВІ ОБРОБКИ ІНФОРМАЦІЇ ОПТИЧНОГО ПОТОКУ В УМОВАХ ЗМІШАНОГО РУХУ
}

\begin{abstract}
Оскільки жодне з технічних засіб навігації не є універсальним ні за обсягом розв'язуваних завдань, ні по застосуванню в різних умовах навігаційної обстановки, то задоволення зростаючих вимог по точності та надійності навігаційних вимірювань в сучасних навігаційних комплексах найчастіше досягається за рахунок оптимальної обробки надлишкової інформації шляхом комплексування систем. При цььому найкращим чином можна недоліки одних вимірників компенсувати перевагами інших, не зачіпаючи при иуьому самих вимірників. У роботі представлений алгоритм корекиї інериійної навігаційної системи безпілотного літального апарату на основі комплексної навігаџіï, щуо базується на обробиі інформації оптичного потоку в умовах зміманого шуму. Це забезпечить високу точність визначення навігаційних параметрів, ивидкість роботи системи корекції, малі габарити та вартість, а також автономність роботи. Даний метод реалізує новий спосіб корекиії інериійної навігаџійної системи. Процедури для вирішення навігаџійних завдань: визначення відносних координат від системи супутникової навігації, від засобів оптичного спостереження за місцевістю (оптичний потік) та інериійної вимірювальної системи безпілотного літального апарату.
\end{abstract}

Ключові слова: інериійна навігаційна система, оптико-електронна система, безпілотний літальний anapam.

\section{Вступ}

Постановка проблеми. При використанні на безпілотних літальних апаратах (БПЛА) інерційної системи наднизької точності (особливо на БПЛА ближньої дії) відсутність коригуючих сигналів від систем навігації може привести до "розвалу" інерційної системи та аварії БПЛА. Також придушення глобальних систем супутникової навігації (ГССН) розглядається в якості основного методу боротьби 3 БПЛА. Застосування високоточних інерційних навігаційних систем також повністю не вирішує проблему з наступних причин:

- такі системи мають високу вартість;

- маса інерційної системи "середньої точності" на лазерних або опто-волоконних гіроскопах становить від 8 кг, що робить проблематичним їх використання на БПЛА малої та навіть середньої дальності;

- принциповим обмеженням інерційних навігаційних систем $є$ зростання помилки визначення координат з часом автономної роботи [1].

Маємо протиріччя: методи, які призводять до поліпшення точності навігації, одночасно призводять до втрати системою автономності. Підходом до розв'язання даного протиріччя є введення відеонавігації спільно з визначенням координат БПЛА по пеленгаційним вимірюванням відносно об'єкту спостереження з відомими координатами.
Аналіз останніх досліджень і публікацій. 3 метою підвищення точності навігаційного комплексу на борту БПЛА проводиться комплексна обробка інформації від автономних систем та коректорів інерційної навігаційної системи з використанням фільтра Калмана [2]. На автономність та завадостійкість радіотехнічних коректорів інерційної навігаційної системи або супутникової системи навігації, впливають геометричні фактори, а також видалення супутникової СН від базової коректуючої станції, що знижує точність визначення координат положення БПЛА. Можливе відключення сигналів супутникової системи навігації $(\mathrm{CH})$ в умовах протидії або при попаданні в “темні” зони або “зриви” супроводження призводять до недостатньо високої надійності та точності навігаційного комплексу при польоті на малих висотах [3]. Прогрес у створенні точних малогабаритних систем автономної корекції помилок інерційної навігаційної системи та у формуванні цифрової картографічної інформації з аерокосмічних знімків і топографічних карт при значному збільшенні обчислювальних можливостей бортових процесорів дозволяють підвищити ступінь автономності комплексних навігаційних систем [4]. Локальна радіотехнічна навігаційна система може досить легко бути інтегрована в системи глобального позиціонування та разом 3 тим 3 більш високою ймовірністю забезпечити потрібну точність 
наведення БПЛА на ціль [2; 5]. Результати розрахунку вихідної потужності передавача шумової перешкоди показують, що навіть малопотужні передавачі шумових перешкод в змозі створити зону придушення супутникової СН радіусом понад 100 км [6].

Метою статті є підвищення точності та автономності навігації БПЛА за рахунок розробки методу комплексної навігації безпілотного літального апарата на основі обробки інформації оптичного потоку в умовах змішаного руху.

\section{Виклад основного матеріалу}

Нехай апріорні припущення про рух БПЛА відсутні. Очевидно, що метод найменших квадратів показує найкращі результати, коли результуючі рівняння є лінійними за всіма параметрами руху. Розглянемо норму, яка приводить до рівнянь, лінійних по деяких невідомих і квадратичних за іншими даними [7]. Необхідно знайти мінімум для норми (1) при обмеженні $T_{x}^{2}+T_{y}^{2}+T_{z}^{2}=1$.

де:

$$
\begin{gathered}
\hat{T}=\min _{T_{x}, T_{y}, T_{z i}, j \in B} \sum_{i j m}^{n \times m} \mathrm{w}_{i j}\left[\left(u_{i j}-\frac{-T_{x} f+T_{z} i}{Z}\right)^{2}+\left(v_{i j}-\frac{-T_{y} f+T_{z} j}{Z}\right)^{2}\right]\left(\alpha^{2}+\beta^{2}\right) ; \\
\alpha=-T_{x}+T_{z} i ; \\
\beta=-T_{y}+T_{z} j ; \\
\mathrm{w}_{i j}=\left\{\begin{array}{l}
1, i f \operatorname{cond}\left(G_{i j}\right)<100, \\
0, i f \operatorname{cond}\left(G_{i j}\right) \geq 100 .
\end{array}\right. \\
T_{x}=\frac{T_{z} \sum_{i, j \in B}^{n \times m} i-Z \sum_{i, j \in B}^{n \times m} u}{(w h)}, \quad T_{y}=\frac{T_{z} \sum_{i, j \in B}^{n \times m} j+Z \sum_{i, j \in B}^{n \times m} v}{(w h)} .
\end{gathered}
$$

Наведені нижче рівняння є поліномами від невідомих $T_{x}, T_{y}, T_{z}, \omega_{x}, \omega_{y}$ i $\omega_{z}$. Вони можуть бути розв'язані стандартними ітераційними методами.

1) Диференціювання виразу (1) відносно $Z$ i

$$
Z=\frac{\alpha^{2}+\beta^{2}}{\left(u-u_{r}\right) \alpha+\left(v-v_{r}\right) \beta} .
$$
прирівнювання отриманого виразу до нуля [8]:

$$
\begin{gathered}
\hat{V}=\min _{\substack{T_{x}, T_{y}, T_{z} \\
\omega_{x}, \omega_{y}, \omega_{z}}} \sum_{i, j \in B}^{n \times m} \mathrm{w}_{i j}\left[\left(u_{i j}-\frac{\omega_{x} j+\omega_{y}\left(i+f^{2}\right)}{f}-\omega_{z} j\right) \beta+\left(v_{i j}-\frac{\omega_{x}\left(j+f^{2}\right)+\omega_{y} i}{f}+\omega_{z} i\right) \alpha\right]^{2}+ \\
+\lambda\left(T_{x}+T_{y}+T_{z}-1\right) ; \\
\mathrm{w}_{i j}=\left\{\begin{array}{l}
1, \text { if } \operatorname{cond}\left(G_{i j}\right)<100, \\
0, \text { if } \operatorname{cond}\left(G_{i j}\right) \geq 100 .
\end{array}\right.
\end{gathered}
$$

3) Визначення параметрів руху (5) шляхом диференціювання рівнянь.
Структурна схема системи побудови поля руху забезпечення навігації для визначення параметрів руху наведена на рис. 1 .

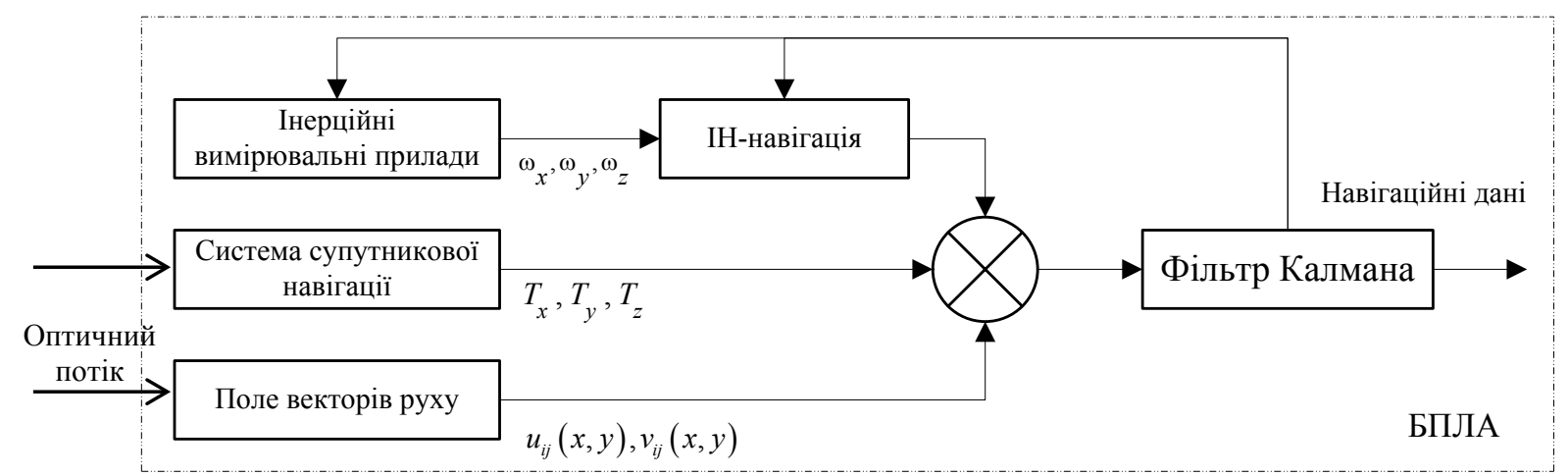

Рис. 1. Структура системи забезпечення комплексної навігації БПЛА Джерело: розроблено авторами за даними [10]. 


$$
\begin{aligned}
& \sum_{i, j \in B}^{n \times m}\left[\left(u-u_{r}\right) \beta-\left(v-v_{r}\right) \alpha\right]\left[-i j \beta+\left(j^{2}+1\right) \alpha\right]=0 ; \\
& \sum_{i, j \in B}^{n \times m}\left[\left(u-u_{r}\right) \beta-\left(v-v_{r}\right) \alpha\right]\left[\left(i^{2}+1\right) \beta-i j \alpha\right]=0 ; \\
& \sum_{i, j \in B}^{n \times m}\left[\left(u-u_{r}\right) \beta-\left(v-v_{r}\right) \alpha\right][j \beta+i \alpha]=0 ; \\
& \sum_{i, j \in B}^{n \times m}\left[\left(u-u_{r}\right) \beta-\left(v-v_{r}\right) \alpha\right]\left[v-v_{r}\right]+\lambda T_{x}=0 ; \\
& \sum_{i, j \in B}^{n \times m}\left[\left(u-u_{r}\right) \beta-\left(v-v_{r}\right) \alpha\right]\left[u-u_{r}\right]+\lambda T_{y}=0 ; \\
& \sum_{i, j \in B}^{n \times m}\left[\left(u-u_{r}\right) \beta-\left(v-v_{r}\right) \alpha\right]\left[\left(u-u_{r}\right) j+\left(v-v_{r}\right) i\right]+\lambda T_{z}=0 ; \\
& T_{x}+T_{y}+T_{z}=1 .
\end{aligned}
$$

До системи надходять дані від трьох незалежних джерел визначення параметрів руху: інерційних вимірювальних приладів, системи супутникової навігації та оптичних датчиків.

Останні задіяні у процесі побудови поля векторів руху. Фільтр Калмана забезпечує адаптацію команд керування БПЛА відповідно до змін обстановки, в якій рухається апарат [9].

На рис. 2 наведена структура методу компле- ксної навігації на основі обробки даних оптичного потоку. Після попередньої фільтрації зображення і перетворення його на півтонове отримане поточне зображення розбивається на блоки розміром $8 \times 8$. Кожний блок піддається оцінці його текстурованості i руху шляхом застосування ієрархічного методу оцінки [11].

За результатами оцінки оптичного потоку будується поле векторів.

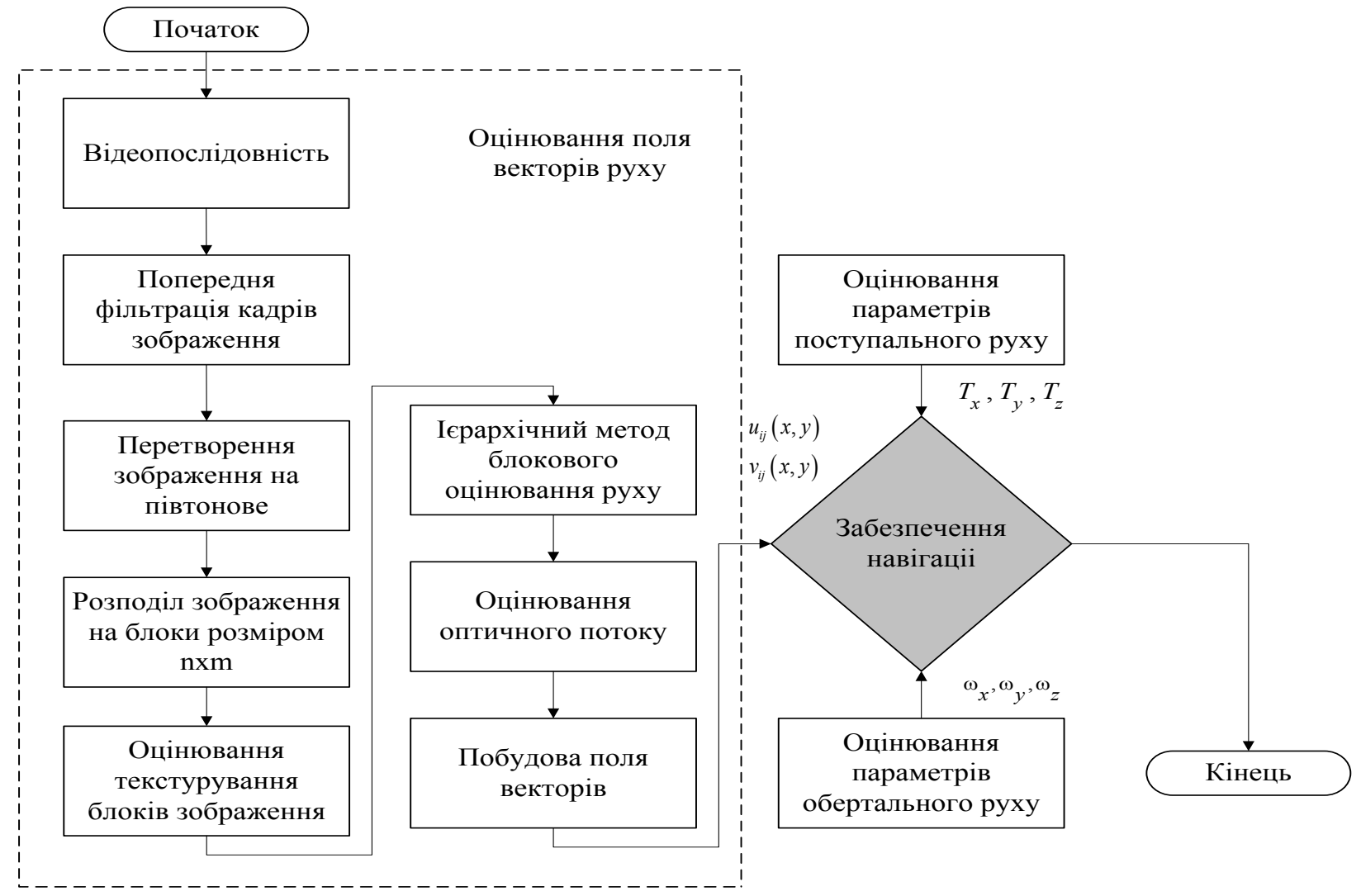

Рис. 2. Етапи методу комплексної навігації на основі обробки даних оптичного потоку Джерело: розроблено авторами. 
Далі визначаються параметри векторів руху (величина і напрямок) зміщення відповідного блоку, які записуються у відповідні матриці. Вибраний алгоритм аналізу векторів руху (поля руху) БПЛА разом 3 оцінками параметрів його поступального та обертального руху, забезпечує навігацію безпілотної системи [12].

\section{Висновки}

Таким чином, розроблений метод комплексної навігації безпілотного літального апарата на основі обробки інформації оптичного потоку в умовах змішаного руху дозволяє здійснювати пасивну навігацію БПЛА в умовах відсутності сигналів ССН.

Це забезпечить підвищення точності та автономності навігації БПЛА за рахунок застосування відео-датчиків для оцінки динамічних параметрів руху в процесі обробки інформації оптичного потоку відеокамери та побудувати поле векторів руху відповідно до проаналізованої текстури земної поверхні.

\section{Список літератури}

1. Харин Е.Г. Комплексная обработка информации навигационных систем летательных аппаратов / Е.Г. Харин. М.: МАИ, 2002. $-260 \mathrm{c}$.

2. Балов А.В Система координатно-временного и навигационно-информационного обеспечения с базированием опорных станций в околоземном воздушном пространстве / А.В. Балов // Новости навигации. - 2009. - № 3. - С. 17-23.

3. Веремеенко К.К. Управление и наведение беспилотных маневренных летательных аппаратов на основе современных информационных технологий / К.К. Веремеенко, А.Н. Головинский, В.В. Инсаров. - М.: Физмалит, 2013. $280 \mathrm{c}$.

4. Лунев Е.М. Повышение точности определения навигационных параметров беспилотного летательного аппарата на базе фотограмметрических измерений на 26 этапе посадки / Е.М. Лунев // Вестник Московского авиационного института. - 2011. - № 2. - С. 150-159.

5. Дятлов А.П. Радиоэлектронная борьба со спутниковыми радионавигационными системами / А.П. Дятлов, П.А. Дятлов, Б.Х. Кульбикаян. - М.: Радио и связь, 2004. - 226 с.

6. Lowe D.G. Object Recognition from Local Scale-Invariant Feature / D.G. Lowe // International conference on Computer Vision. - London, 1999. - P. 1150-1157.

7. Lowe D.G. Distinctive Image Features from Scale-Invariant Keypoints / D.G. Lowe // International conference on Computer Vision. - London, 2004. - P. 91-110.

8. Bay H. Surf: Speeded up robust features / H. Bay, T. Tuytelaars, L. Van Gool [Electronic resource] // European Conference on Computer Vision. - № 1. - 2006. - P. 404-407. - Available at: https://www.researchgate.net/publication/225761164_SURF_Speeded_up_robust_features.

9. Morel J. ASIFT: New Framework for Fully Affine Invariant Image Comparison / J. Morel, G. Yu // SIAM Journal on Imaging Sciences. - 2009. - № 2(2). - P. 438-469.

10. Image Quality Assessment: From Error Measurement to Structural Similarity / Z. Wang, A.C. Bovik, H.R. Sheikh, E.P. Simoncelli // IEEE Transactions on image processing. - 2004. - № 13(1). - P. 600-612.

11. Погурельський О.С. Переваги методу спільної обробки даних від навігаційних систем GPS та ГЛОНАCС / О.С. Погурельський // Збірник тез доповідей VII наукової конференції Харківського університету Повітряних Сил ім. І. Кожедуба "Новітні технології - для захисту повітряного простору”. - Харків, 2011. - С. 263.

12. Феоктистов Д.С. Исследование алгоритмов решения навигационных задач / Д.С. Феоктистов // Современные проблемы радиоэлектроники. - 2013. - № 2(3). - С. 202-207.

\section{Відомості про авторів:}

\section{Кривоножко Анатолій Миколайович}

\section{Командувач}

Повітряного Командування “Центр”,

Васильків, Україна

https://orcid.org/0000-0002-1470-7301

\footnotetext{
Явтушенко Володимир Олексійович старший викладач

Харківського національного університету

Повітряних Сил ім. І. Кожедуба,

Харків, Україна

https://orcid.org/0000-0003-2915-0427
}

\section{Information about the authors:}

\author{
Anatolii Krivonozhko \\ Commander \\ of the Air Command "Center", \\ Vasylkiv, Ukraine \\ https://orcid.org/0000-0002-1470-7301
}

\author{
Vladimir Yavtushenko \\ Senior Instructor \\ of Ivan Kozhedub Kharkiv \\ National Air Force University, \\ Kharkiv, Ukraine \\ https://orcid.org/0000-0003-2915-0427
}


Самокіш Артем Валерійович

ад'юнкт

Харківського національного університету

Повітряних Сил ім. І. Кожедуба,

Харків, Україна

https://orcid.org/0000-0003-1924-9351

\section{Воробйов Свген Сергійович}

викладач

Харківського національного університету

Повітряних Сил ім. I. Кожедуба, Харків,

Україна

https://orcid.org/0000-0002-1828-0069

\author{
Artem Samokish \\ Doctoral Student \\ of Ivan Kozhedub Kharkiv \\ National Air Force University, \\ Kharkiv, Ukraine \\ https://orcid.org/0000-0003-1924-9351
}

\author{
Yevhen Vorobyov \\ Instructor \\ of Ivan Kozhedub Kharkiv \\ National Air Force University, \\ Kharkiv, Ukraine \\ https://orcid.org/0000-0002-1828-0069
}

\section{РАЗРАБОТКА МЕТОДА КОМПЛЕКСНОЙ НАВИГАЦИИ БЕСПИЛОТНОГО ЛЕТАТЕЛЬНОГО АППАРАТА НА ОСНОВЕ ОБРАБОТКИ ИНФОРМАЦИИ ОПТИЧЕСКОГО ПОТОКА В УСЛОВИЯХ СМЕШАННОГО ДВИЖЕНИЯ}

А.Н. Кривоножко, В.А. Явтушенко, А.В. Самокиш, Е.С. Воробйов

Поскольку ни одно из технических средств навигации не является универсальным ни по объему решаемых задач, ни по применению в различных условиях навигачионной обстановки, то удовлетворения растущих требований по точности и надежности навигационных измерений в современных навигационных комплексах зачастую достигается за счет оптимальной обработки избыточной информации путем комплексирования систем. При этом наилучшим образом можно недостатки одних измерителей компенсировать преимуществами других, не затрагивая при этом самих измерителей. В работе представлен алгоритм коррекции инериионной навигационной системы беспилотного летального аппарата на основе комплексной навигации, основанной на обработке информачии оптического потока в условиях смешанного шума. Это обеспечит высокую точность определения навигаиионных параметров, скорость работы системы коррекиии, малые габариты и стоимость, а также автономность работы. Данный метод реализует новый способ коррекции инеричинной навигационной системы. Прочедуры для решения навигационных задач: определение относительных координат от системы спутниковой навигации, от средств оптического наблюдения местности (оптический поток) и инериионной измерительной системы беспилотного летательного аппарата.

Ключевые слова: инерционная навигационная система, оптико-электронная система, беспилотный летательный annapam.

\section{DEVELOPMENT OF A COMPREHENSIVE NAVIGATION METHOD FOR UNMANNED AIRCRAFT BASED ON OPTICAL FLOW INFORMATION PROCESSING IN CONDITIONS OF MIXED MOTION}

A. Krivonozhko, V. Yavtushenko, A. Samokish, Ye. Vorobyov

Since none of the technical means of navigation is universal either in terms of the scope of the tasks being solved, or in terms of application in various conditions of the navigation environment, the satisfaction of the growing requirements for the accuracy and reliability of navigation measurements in modern navigation systems is often achieved through optimal processing of excess information by complexing systems. In this case, in the best possible way, the disadvantages of some meters can be compensated for by the advantages of others, without affecting the meters themselves. The paper presents an algorithm for correcting the inertial navigation system of an unmanned aerial vehicle based on integrated navigation based on the processing of optical flow information under mixed noise conditions. This will provide high accuracy in determining navigation parameters, speed of the correction system, small size and cost, as well as autonomy. This method implements a new way of correcting the inertial navigation system based on a developed mathematical model describing the procedures for solving navigation problems: determining the relative coordinates from the satellite navigation system, from the means of optical observation of the terrain (optical flow) based on landmarks on the ground and an inertial measurement system of the unmanned aerial vehicle. The coordinate system is an optoelectronic system, enumerates the obtained relative coordinates using a matrix of direction cosines into a geographic coordinate system; determination of the geographical coordinates of identical points from an electronic map of the area; calculating the current geographic coordinates of the unmanned aerial vehicle based on its relative coordinates and the geographic coordinates of identical points. The solution of the described tasks is carried out by the developed method, the final step of which is the introduction of the current geographical coordinates of the unmanned aerial vehicle into the inertial navigation system for its correction.

Keywords: inertial navigation system, optoelectronic system, unmanned aerial vehicle. 